\title{
Dynamic Crack Propagation and its Interaction with Micro-Cracks in an Impact Problem
}

\author{
Adem Candaş ${ }^{1}$ \\ Faculty of Mechanical Engineering, Istanbul Technical University, Beyoğlu, Istanbul, \\ 34437, Turkey \\ candas@itu.edu.tr \\ Erkan Oterkus \\ Department of Naval Architecture, Ocean and Marine Engineering, University of \\ Strathclyde, Glasgow G4 OLZ, United Kingdom \\ erkan.oterkus@strath.ac.uk \\ Cevat Erdem İmrak \\ Faculty of Mechanical Engineering, Istanbul Technical University, Beyoğlu, Istanbul, \\ 34437, Turkey \\ imrak@itu.edu.tr
}

\begin{abstract}
The dynamic fracture behavior of brittle materials that contain micro-level cracks should be examined when material subjected to impact loading. We investigated the effect of micro-cracks on the propagation of macro-cracks that initiate from notch tips in the Kalthoff-Winkler experiment, a classical impact problem. To define pre-defined micro-cracks in three-dimensional space, we proposed a two-dimensional micro-crack plane definition in the bond-based Peridynamics (PD) that is a non-local form of classical continuum theory. Randomly distributed micro-cracks with different number densities in a constant area and number in expending area models were examined to monitor the toughening of the material. The velocities of macrocrack propagation and the time required for completing of fractures were considered in several pre-defined micro-cracks cases. It has been observed that toughening mechanism only initiated by exceeding a certain
\end{abstract}

\footnotetext{
${ }^{1}$ Corresponding author: Adem Candaş candas@itu.edu.tr
} 
number of micro-cracks; therefore, there is a positive correlation between the density of pre-defined microcracks and macro-crack propagation rate and also, toughening mechanism.

\section{INTRODUCTION}

The crack initiation and propagation under impact loading is a problem that has received considerable attention because of its technical consequences. Both macro and related micro level cracks may adversely affect the operation of the system especially in cases where brittle structural elements subjected to impact load. Brittle materials have advantages such as hardness and wear resistance, but their deficiencies in terms of toughness and brittleness significantly restrain their usage in practice. This is the main reason that the problem of crack propagation at both macro and micro levels is a problem of frequent discussion in the recent literature [1-4].

Due to high stress concentrations, pre-existing micro-cracks appear in many brittle materials [5]. The presence of micro-cracks around the tip of a macro-crack may lead to crack shielding or crack amplification and affect crack propagation significantly [6]. The amplification increases the stress intensity factors around the crack tip, whereas the shielding reduces them. Recent studies have stated that the micro-cracks and as a consequence, the shielding increases material toughness $[7,8]$. This phenomenon is called as "micro-crack toughening" [4]. Location, orientation, and density of micro-cracks significantly alter the toughening mechanism and crack propagation due to changes in stress intensity around the main crack [9-11]. Examining the effect of non-uniformly arranged micro-cracks with analytical approaches is rather complicated due to complex 
mechanical behavior [4]. Some analytical solutions were presented for uniformly distributed micro-cracks [12-16]. Several researchers investigated the effect of microcracks on the propagation of the main crack and obtained solutions with analytical approximations under certain restrictive assumptions $[9,12,17,18]$. Tamuzs and Petrova [19] presented a review of studies that focus on problems and methods to investigate macro-crack growth in materials with micro-damages.

Finite element method (FEM) has been used with some modifications such as cohesive-zone [20], element-erosion [21], and extended-FEM (XFEM) [22] to simulate crack propagation with a numerical approach. The restriction of crack propagation path with element boundaries causes to obtain inaccurate results in element-erosion and the cohesive-zone techniques [23]. Although some researchers [24-31] stated that the XFEM is a useful method for simulating crack propagation, it is necessary to adjust the input fracture energy to examine the dynamic fractures precisely [23, 32]. Moreover, complexity and cost as a result of the sub-division of cut elements are other disadvantages of crack propagation modeling with XFEM [32]. Rabczuk et al. [33] and Kosteski et al. [34] studied the dynamic crack propagation with discrete element models. Braun and Fernández-Sáez [35] suggested a 2D discrete model and applied it to the benchmark problem in [36], though crack paths were lattice dependent for coarse meshes. Therefore, a more comprehensive and robust approach is a considerable requisite to determine crack nucleation, propagation, and interactions [4]. Silling and Askari [37] presented Peridynamics (PD) method, which naturally involves crack modeling, nucleation, and progression in a continuum, and thus overcomes the deficiencies of classical numerical 
approaches. Silling [38] established PD as a non-local form of continuum mechanics. PD is a non-local formulation in an integral form in contrast to the local differential form of classical continuum mechanics [39]. In PD, a continuum body is defined with material points (particles) that have a volume in space. Each material points can interact with points located with a certain distance that is defined as the horizon. The interaction forces between a material point with other points in the horizon determines the behavior of that point. Since PD is based on integro-differential equations instead of spatial derivatives, it complies with problems comprising discontinuities such as cracks [38]. Silling and Lehoucq [40] conducted a convergence study of force densities of PD and the classical elasticity theory to examine the robustness and efficiency of the theory. Besides some researchers applied PD theory in different applications, such as coupling of PD and FEM for failure prediction [41, 42], damage propagation in layered glass under impact loading [43], for anisotropic materials [44], problems of heat conduction [45, 46], cracks generated from corrosion pits [47], and examining composite laminates under explosive loading [48]. Madenci and Oterkus [49] published a book that consist of detailed explanations of the theory with different applications and extensive literature surveys.

Rubinstein [12], Rose [9], Brencich and Carpinteri [7] presented analytical methods for investigation of micro/macro- crack interaction with uniformly distributed micro-crack patterns. The solutions belong to the problem of the interaction of intricate micro-crack patterns are not widely presented in the current literature [4]. One of the most recent studies on the effect of small cracks on the propagation of a macro-crack is presented in [3]. They provide a relation between various locations, density, and numbers 
of cracks and macro-crack propagation speed. The models considered in that study are single crack collinear to the main crack, two symmetrical cracks, and horizontal and transverse array of cracks. Another study carried out by Basoglu et al. [4] present arbitrary micro-crack patterns by using the same bond-based PD models. They observed that a crescent-like micro-crack distribution near the macro-crack tip cause the highest shielding effect and so that a considerable increase has shown in material toughness. In both studies, two-dimensional plates involving macro-cracks along their mid-axis are subjected to displacement-controlled tensile-load. In this study, we proposed a two-dimensional micro-crack definition in a three-dimensional body and extended the cases in previous studies to simulate the stochastically distributed micro-cracks around the macro-crack tip. We aimed at a realistic approach to investigate the micro-crack toughening mechanism by creating disordered two-dimensional micro-cracks in a three-dimensional body. For this purpose, we have examined the problem described by Kalthoff and Winkler in $[36,51]$ and presented numerical solutions using the PD method in $[49,50,52]$.

In recent years, several authors have suggested various approaches to the modeling of the Kalthoff-Winkler problem. Silling [50] presented the PD solution of the problem as a part of the validation process of PD theory. The crack propagation angle from the vertical axis was determined by bond-based PD in [49]. Ren et al. [53, 54] proposed the dual horizon PD formulation to reduce the calculation cost and examined the problem in this aspect. Amani et al. [55] proposed the implementation of state-based PD for thermoplasticity to simulate the Kalthoff-Winkler problem effectively. Gu et al. [56] extend this study by implementing non-uniform discretization and Voronoi diagrams in 
PD. Also, the effect of plate dimensions and model parameters such as impact velocity, plate thickness on the crack propagation speed, and the crack angle were investigated with the state-based PD model [57]. Moreover, Trask et al. [58] applied a meshfree quadrature rule for the discretization of PD material points and verified the model with results from the Kalthoff-Winkler experiment. On the other hand, a reformulated thermovisco-plastic model study was made to demonstrate the effect of impact velocity on the crack propagation speed [59]. To authors best knowledge, the effect of micro-cracks on crack propagation in a material subjected to an impact load stands out as a gap in the literature that needs further investigation. Therefore, in this study, we applied bondbased PD to monitor the effect of micro-cracks on dynamic crack propagation. We focused on examining the relationship between stochastically pre-defined defects and the toughening mechanism in the Kalthoff-Winkler problem by using bond-based PD. A two-dimensional micro-crack definition and examining the effect of stochastically prelocated micro-cracks on the three-dimensional body by using PD theory are considered as a novel approach. The bond-based PD theory and two-dimensional micro-crack definition are briefly explained in Sec. 2. The reference impact problem, results of numerical studies, and discussions are given in Sec. 3. The conclusion is presented in Sec. 4. 


\section{METHODOLOGY}

The equation of motion, its discretization form, and the damage definition in Peridynamic theory and micro-crack definition are given in this section.

\subsection{Peridynamic Formulation}

Silling [38] presented PD theory to overcome the problem of the mathematical framework that is inoperative for discontinuous situations such as crack formation in classical continuum mechanics. The use of partial derivatives to define the relative displacement and force between two particles results in the fact that the equations are undefined in discontinuity regions naturally. PD's equation of motion is based on integral equations, so that it is applicable for both continuity and discontinuity zones. In the bondbased PD theory, firstly presented in [38], force density vectors between two material points are equal in magnitude and being parallel. This formulation has been extended to state-based PD formulation by Silling et al. [52], which defines force density vectors unequal in terms of magnitude. The equation of motion in bond-based PD theory for any material point is given in [37] as follows:

$$
\rho \ddot{\mathbf{u}}(\mathbf{x}, t)=\int_{\mathcal{H}_{\mathbf{x}}} \mathbf{f}\left(\mathbf{u}\left(\mathbf{x}^{\prime}, t\right)-\mathbf{u}(\mathbf{x}, t), \mathbf{x}^{\prime}-\mathbf{x}\right) \mathrm{d} V_{\mathbf{x}^{\prime}}+\mathbf{b}(\mathbf{x}, t)
$$

where $\mathcal{H}_{\mathrm{x}}$ is a spherical region with radius $(\delta)$ called horizon, $\mathbf{x}^{\prime}$ is a family member of the material point $\mathbf{x}$ inside its horizon, $\mathbf{u}$ is the displacement vector, $\mathbf{b}$ is the body load, $\rho$ is the mass density, $\mathbf{f}$ is the force vector that the material point $\mathbf{x}^{\prime}$ exerts on particle $\mathbf{x}$, and $\mathrm{d} V_{\mathbf{x}^{\prime}}$ is the infinitesimally small volume of point $\mathbf{x}^{\prime}$. The relative position vector between two material points in the undeformed state is denoted as $\boldsymbol{\xi}=\mathbf{x}^{\prime}-\mathbf{x}$ and $\boldsymbol{\eta}=$ $\mathbf{u}\left(\mathbf{x}^{\prime}, t\right)-\mathbf{u}(\mathbf{x}, t)$ denotes the relative displacement vector after deformation (Fig. 1). 
Moreover, $\mathbf{y}^{\prime}-\mathbf{y}=\mathbf{\eta}+\boldsymbol{\xi}$ is the relative position vector in the deformed configuration $[37,49]$.

When a material is considered as micro-elastic, it can be said that the bond between the two material points can be evaluated as an elastic spring and a scalar micropotential function in a single bond can be written as:

$$
w(\boldsymbol{\eta}, \xi)=\frac{1}{2} c s^{2}|\xi|
$$

where the bond-constant $c=12 E / \pi \delta^{4}$ is obtained by comparing the energy densities of PD and classical continuum theory for three-dimensional structures and the bond stretch can be expressed as $s=(|\xi+\eta|-|\xi|) /|\xi|$ [49]. The derivative of micropotential gives the pairwise force function $f$, as:

$$
\frac{\partial w}{\partial \boldsymbol{\eta}}(\boldsymbol{\eta}, \xi)=\mathbf{f}(\boldsymbol{\eta}, \xi)=\frac{\xi+\boldsymbol{\eta}}{|\xi+\boldsymbol{\eta}|} f(|\xi+\boldsymbol{\eta}|, \xi) \quad \forall \boldsymbol{\eta}, \xi
$$

where $f$ is a scalar-valued function and it is expressed as follows:

$$
f(|\xi+\eta|, \xi)=c S
$$

It is usually not possible to solve the PD equation of motion given in (1) by analytical tools. Hence, the initial continuum body is discretized into points that have specific volumes to solve the PD equation of motion. The discretized form of the governing equation for the material point $k$ by considering all material points inside the horizon can be written as:

$$
\rho_{k} \ddot{\mathbf{u}}_{k}^{n}=\sum_{j} \mathbf{f}\left(\mathbf{u}_{j}^{n}-\mathbf{u}_{k}^{n}, \mathbf{x}_{j}-\mathbf{x}_{k}\right) V_{j}+\mathbf{b}_{k}^{n}
$$

where $\mathbf{u}_{k}^{n}$ represents the displacement of a material point $k$ at the $n^{\text {th }}$ timestep. The volume of material point $j$ is defined as $V_{j}=(\Delta x)^{3}$ in a three-dimensional problem where $\Delta x$ denotes the constant grid spacing [37]. 
In PD, the failure criteria can be considered as the bond is broken when the bondstretch $s$, between two material points exceeds a pre-defined critical-stretch value $s_{c}$. Considering a bond is not recoverable after failure, a history-dependent scalar-valued step function $\mu(t, \xi)$ can be combined with the bond-force equation as:

$$
f(|\xi+\eta|, \xi)=c s \mu(t, \xi)
$$

where

$$
\mu(t, \xi)=\left\{\begin{array}{ll}
1 & \text { if } s\left(t^{\prime}, \xi\right)<s_{c} \\
0 & \text { otherwise }
\end{array} \text { for all } 0 \leq t^{\prime} \leq t\right.
$$

The local damage parameter for a material point concerning broken bonds is defined as:

$$
\varphi(\mathbf{x}, t)=1-\frac{\int_{\mathcal{H} \mathbf{x}} \mu(\mathbf{x}, t, \xi) \mathrm{d} V_{\xi}}{\int_{\mathcal{H}_{\mathbf{X}}} \mathrm{d} V_{\xi}}
$$

\subsection{Micro-Crack Definition}

In many engineering applications, cracks may have existed in structures at different positions, angles, and lengths. In PD, removing bonds passing through crack surfaces is a suitable approach to determine a pre-defined crack. Madenci and Oterkus [49] examined the damage value of the material points by considering their location with respect to the crack surface. They showed that material points close to the crack tips might have different damage values with respect to the other material points around the crack region. Fig. 2 shows a pre-defined crack plane and material points exposed to bondbreakage due to the intersection of bonds with this plane. The plane of the pre-defined crack may be located at any position between the material points in the presented model. As shown for an exemplary material point, the bonds between the material point and its 
family members are considered to vanish when they intersect the crack plane. The material points whose horizon intersects with the crack plane are damaged at specific amounts, as shown on the color scale (Fig. 2). The amount of damage is directly related to the proximity to the plane of the fracture and the points closest to the crack plane suffer more damage than distant ones. The length of the crack plane can be adjusted to determine whether the fracture is a micro or macro-crack. An algorithm is given in Fig. 3 to detect and break the bonds due to the crack.

\section{NUMERICAL EXAMPLES}

In this section, the results of numerical examples of the Kalthoff-Winkler problem that contain pre-defined micro-cracks are given by employing the bond-based PD theory. Firstly, we demonstrate "the crescent-shaped micro-crack pattern" case defined in [4] to show that the micro-crack definition and the bond-based PD implementation are applicable for the Kalthoff-Winkler problem. Then, the effects of the location of microcracks and their density on the crack propagation velocity are presented.

The Kalthoff-Winkler experiments [36], was performed with the high strength maraging steel plate (X2NiCoMo 1895 ) having two parallel notches. It is impacted by a steel impactor as shown in Fig. 4a. The material properties of the steel plate are the same as in [49] and given in Table 1. Kalthoff [51] stated that the high strength maraging steel shows an almost linear-elastic behavior and the linear elastic equations can describe the stress distribution around the crack tip. When shear bands control the fracture at high rates of loading, crack propagation is nearly parallel to the notch (Mode II). On the other 
hand, at low rates of loading, a mode transition occurs. The crack propagates as Mode I and micro-elastic PD theory is valid to simulate this brittle fracture as stated by Silling [50]. As indicated in [36], the impact of projectile with a certain velocity results in a brittle fracture in the target body and our study only focused on this failure mode. The dimensions of the plate are $L=0.200 \mathrm{~m}, W=0.100 \mathrm{~m}$, and $h=0.009 \mathrm{~m}$. The distance between the notches (slits) is $d=0.050 \mathrm{~m}$ and they are located symmetrically with a length of $a=0.050 \mathrm{~m}$. The notch thickness is $n=0.0015 \mathrm{~m}$. In the initial state, plate boundaries are traction-free and at rest. The cylindrical impactor is assumed to be a rigid body with sizes of $D=\phi 0.050 \mathrm{~m}$ and $H=0.050 \mathrm{~m}$. The mass of the impactor is $1.57 \mathrm{~kg}$. The velocity of the impactor is $v=-32 \mathrm{~m} / \mathrm{s}$ through the $y$-axis.

The discretized model of the steel body is generated with $201 \times 101 \times 9$ material points along $x, y$, and $z$-axis, respectively (Fig. 4b). The spacing between material points (grid size) is determined as $\Delta=0.001 \mathrm{~m}$ in all directions and the radius of the horizon is $\delta=3.015 \times \Delta$ as stated in [49]. The total number of particles is 180873 . The time step is specified as $\Delta t=8.7 \times 10^{-8} s$ and the critical stretch is defined as $s_{c}=0.01$ as suggested in [49].

\subsection{Benchmark Problem}

Various micro-crack pattern models to examine the effect of micro-cracks on the toughening mechanism and the macro-crack propagation speed was studied in [4]. They proposed that the crescent-like distribution of micro-cracks is the most effective among all models to resist the crack propagation and increase the toughness of the material. In 
the benchmark problem, we adapted the crescent-shaped micro-crack pattern to the Kalthoff-Winkler experiment. In Fig. 5, pre-defined micro-cracks are placed around the notch tip and along the main crack path that was observed in the reference model of the Kalthoff-Winkler experiment without micro-cracks (Fig. 6a). In the reference model, no micro-cracks are defined in the material as in the experiment and there are only two notches that dominate the initiation points of macro-cracks. The main crack initiates the propagation at $30.5 \mu \mathrm{s}\left(350^{\text {th }}\right.$ timestep). The crack propagation reaches the right and left edges at $91.4 \mu \mathrm{s}\left(1050^{\text {th }}\right.$ timestep) (Fig. 6a) and the average velocity is $1345 \mathrm{~m} / \mathrm{s}$. Considering the required time for cracks to reach edges, all models in this study were run to $117.5 \mu \mathrm{s}\left(1350^{\text {th }}\right.$ timestep) to observe the damage path properly. The damage pattern of the benchmark model at $91.4 \mu \mathrm{s}$ is presented in Fig. 6b. In the benchmark problem, the main crack starts occurring at $30.5 \mu$ s as same with without micro-crack model. However, the crack cannot reach the edge at $91.4 \mu$ s due to the decrease of propagation velocity. The crack propagation reaches the edge at $95.7 \mu s\left(1100^{\text {th }}\right.$ timestep) (Fig. $\left.6 \mathrm{~d}\right)$ and the average velocity is $1188 \mathrm{~m} / \mathrm{s}$. Herein, the crack propagation velocity of benchmark model with micro-cracks reduces about $12 \%$ as compared to the original experiment model. Brencich and Carpinteri [7] stated that opening and coalescence of micro-cracks cause stress redistribution and energy dissipation mechanisms. Using of part of input mechanical energy by the pre-existing micro-cracks weaken the propagation of main crack and thus, creates shielding effect which is called toughening by micro-cracks. The deceleration in main macro-crack velocity is a result of this toughening mechanism. 
Therefore, validation study confirms that presence of micro-cracks can cause a fracture toughening effect that reduces the crack propagation velocity in our simulation.

\subsection{Stochastically Distributed Micro-Cracks}

It is more challenging to analyze randomly distributed micro-cracks with analytical methods. Thus, with the bond-based PD method, we examined the effects of micro-cracks on macro-crack propagation by varying micro-crack amounts and densities.

\subsubsection{Micro-Cracks with Varying Densities}

In this section, three different densities of micro-crack cases are investigated in the reference region that is defined as in Fig. 7. The micro-crack patterns are stochastically determined and they are with the same length. In the first model, the default density of micro-cracks in the reference zone is defined as $n_{0}=N_{0} / A_{0}$ where $N_{0}$ is the number of micro-cracks and $A_{0}$ is the area of the reference region. The three simulations are performed with varying density of micro-cracks, $n_{0}=\{0.75,1,1.25\}$ in the reference area $A_{0}$. The results of the parameterized density of micro-cracks are used to compare the crack propagation speed of without micro-cracks case. In Fig. 8a, the simulation of the original experiment, without micro-cracks is given for comparison purposes. In this model, macrocracks start to propagate at $30.5 \mu \mathrm{s}$. Macro-cracks reach edges approximately at $91.4 \mu \mathrm{s}$. In Fig. $8 \mathrm{~b}$, the density of micro-cracks in the reference area $\left(A_{0}\right)$ is assigned as $n_{0} \times 0.75$ and the macro-cracks propagation is given at $91.4 \mu \mathrm{s}$. It can be seen that the macro-cracks reach the edge within the same time according to the case without micro-cracks. The case of $n_{0} \times 1$ is shown in Fig. 8c. When the tip of macro-cracks at $91.4 \mu \mathrm{s}$ is examined, the 
propagation speed of macro-cracks decreases with the increase of the density of microcracks and macro-cracks can precisely reach the edge after $91.4 \mu \mathrm{s}$. In Fig. 8d, the density of micro-cracks is increased compared to the reference model with multiplier 1.25. Propagation of macro-cracks slows down more according to without micro-cracks, $n_{0} \times 0.75$, and $n_{0} \times 1$ cases. However, due to the change in macro-cracks propagation path angle, cracks reach the edge approximately at the same time as the $n_{0} \times 1$ case. The crack patterns of all simulations are nearly straight and very similar to patterns in $[49,53$, $54,56,57]$. Once macro-cracks pass over the reference zone of micro-cracks, velocities of macro-crack tips can be determined for each model. In Fig. 9, we present the velocity data after $52.2 \mu$ s when the macro-crack tips can be observable after passing the reference region of micro-cracks. Considering that macro-cracks reaching the edge of the body at 91.4 $\mu s$ in the case of without micro-cracks, the velocity comparisons should be considered up to this time. Therefore, crack propagation without micro-cracks and with pre-determined micro-cracks with different densities are quantitatively compared by calculating the velocities of macro-crack tips from 52.2 to $91.4 \mu \mathrm{s}$. The average velocities in without microcrack case and with micro-crack cases with densities $n_{0} \times\{0.75,1,1.25\}$ are $1345 \mathrm{~m} / \mathrm{s}$, $1327 \mathrm{~m} / \mathrm{s}, 1284 \mathrm{~m} / \mathrm{s}$, and $1165 \mathrm{~m} / \mathrm{s}$, respectively. In without micro-crack case, average velocities and the trend agree with models in $[25,34,35]$ that validates our approach to the problem. Moreover, Gu et al. [56] and Guo and Gao [57] emphasized that the macro-crack initiation time is about $30 \mu \mathrm{s}$ that is very close the values in the experiment $(29 \mu \mathrm{s})$ and our model $(30.5 \mu s)$. Without micro-cracks and the low- density of micro-cracks $\left(n_{0} \times 0.75\right)$ conditions show similar trends since, their velocities are very close to each other. In addition 
to this, in the case of $n_{0} \times 1$, the trend seems to be similar despite the average velocity decreases. In without micro-cracks and $n_{0} \times 0.75$ models, the macro-crack propagation velocities reach a maximum in approximately $60.9 \mu \mathrm{s}$. However, in the cases of $n_{0} \times 1$ and $n_{0} \times 1.25$ macro-cracks the time to reach the maximum speed has a delay with $65.3 \mu \mathrm{s}$ and $78.3 \mu$ s, respectively. In addition to this, while the velocity profiles of the without microcrack and $n_{0} \times 0.75$ cases are very similar, more dense models $\left(n_{0} \times 1\right.$ and $\left.n_{0} \times 1.25\right)$ lead to deceleration in macro-crack propagation according to their number of micro-cracks. In conclusion, our models show that number of micro-cracks in the same area is an important parameter in toughening mechanism. Besides, in $n_{0} \times 1.25$ case, the initial velocity is quite low compared to the other three models. Overall, considering the trends of the four models together, it is observed that velocity differences between models decrease as the macrocracks approach edges of the body.

\subsubsection{Micro-Cracks with Various Number}

In this section, the effect of number of micro-cracks on the toughening mechanism is investigated. We define two more micro-crack zones around the notch tips. The densities of micro-cracks are preserved as $n_{0}$ in all three zones by changing the number of micro-cracks according to the area of regions. In Fig. 10, geometrical details of $A_{0}$ : the reference area in the previous section, $A_{1}$ : the inner area, and $A_{2}$ : the outer area including $A_{0}$ and $A_{1}$ are given. These regions that contain several micro-cracks proportional to their area are compared to the original experiment simulation as in Sec. 3.2.1. Macro-crack propagation without micro-cracks is presented in Fig. 11a. In the inner region $A_{1}$, the 
pattern that contains the least number of micro-cracks does not produce a significant change in the propagation of macro-cracks (Fig. 11b). The required time for macro-cracks to reach the vertical edge is the same as in without micro-cracks case (91.4 $\mu \mathrm{s})$. Microcrack pattern in the region $A_{0}$ decreases the macro-crack propagation velocity. As seen in Fig. 11c, the macro-cracks can reach the edge exactly after $91.4 \mu \mathrm{s}$. The region $A_{2}$ contains the greatest number of micro-cracks that are defined by increasing the number of microcracks with keeping constant the density. The crack propagation path obtained from the simulation result can be seen in Fig. 11d. While complete fracture occurs at $91.4 \mu \mathrm{s}$ in without micro-cracks case, macro-crack propagation in $A_{2}$ case cannot reach vertical edges of the body before $104.4 \mu$ s due to the high number of micro-cracks. In Fig. 12, as stated in previous section, macro-crack propagation velocities between the 52.2 and 91.4 $\mu$ s are given for the without micro-cracks and with micro-cracks cases $\left(A_{0}, A_{1}\right.$, and $\left.A_{2}\right)$. Average velocities during that time interval are $1345 \mathrm{~m} / \mathrm{s}, 1284 \mathrm{~m} / \mathrm{s}, 1347 \mathrm{~m} / \mathrm{s}$, and 1219 $\mathrm{m} / \mathrm{s}$, respectively. Although some deviations are observed at $74.0 \mu \mathrm{s}, 78.3 \mu \mathrm{s}$, and 87.0 $\mu s$, propagation of cracks in the cases without micro-cracks and the $A_{1}$ are very similar. Therefore, it can be deduced that toughening mechanism can only be triggered with a sufficient number of micro-crack cluster. However, there is a significant reduction in the average velocity of the reference area case $A_{0}$ and the largest area case $A_{2}$. The acceleration of the cracks tip in the $A_{0}$ and $A_{2}$ cases show similar trends with the other cases. On the other hand, the profiles reach their maximum velocities with a delay as compared to other models. In the cases of without micro-cracks and $A_{1}$ maximum values are reached at about $60.9 \mu \mathrm{s}$, while in $A_{0}$ and $A_{2}$ cases, the maximum velocities are 
reached at $65.3 \mu$ s and $69.6 \mu$ s, respectively. Also, velocity differences between four models decrease as the time advances. Guo and Gao [57] explained the crack propagation and dynamic failure according to the wave propagation, especially "compressive wave" in [51]. They stated that Mode II crack propagation is driven by this wave until $60 \mu$ s. After that time, the shape of compressional wave is distorted and the effective Mode II crack propagation ends. After that, waves reflected by the boundary drive the crack propagation and weaken the propagation process [57]. The micro-cracks that are located on the path of compression waves can cause a distortion effect on these waves. Thus, shape of waves becomes vague early and its effect on the crack propagation weaken. In our study, the maximum velocity of without micro-cracks case is observed at $60.9 \mu$ s (Fig 9. and Fig. 12). Conversely, maximum values are delayed to 65.3 and $69.6 \mu \mathrm{s} \mathrm{(Fig.} \mathrm{12)} \mathrm{and}$ even to $78.3 \mu \mathrm{s}$ (Fig. 9) and average velocities decrease in cases that have sufficient microcrack patterns in terms of toughening mechanism. Hence, the delay to reach the maximum velocities and the decrease of average velocities can be caused by compression waves being distorted early and reaching the edge lately because of micro-cracks on the wave path.

\section{CONCLUSION}

In this paper, the bond based Peridynamics (PD) model was proposed to investigate the effect of micro-cracks on the material toughness for an impact loading problem. While the less density of stochastically located micro-cracks around the crack tip has no effect on toughening mechanism, adding more micro-cracks in the same area 
can reduce the crack tip velocity and increase the toughness with an appreciable difference. We also investigate the effective number of micro-cracks that cause the toughening. The results show that insufficient number of micro-cracks are inadequate to slow down crack tip's propagation velocities. To obtain the toughening effect, a certain number of pre-defined micro-cracks should be built in the body. In conclusion, the density of micro-cracks in a constant area and the number of micro-cracks in expanding areas are significant parameters on toughening mechanism of a material and using fracture modeling competence of PD can help to improve our understanding on design of more endurance geometries. Our modelling results provide the solution of certain cases, either the length or distances of micro-cracks can be investigated in future studies. 


\section{REFERENCES}

[1] Hutchinson, J. W., 1987, "Crack tip shielding by micro-cracking in brittle solids," Acta Metallurgica, 35(7), pp. 1605-1619. DOI: 10.1016/0001-6160(87)90108-8

[2] Zhou, T., Huang, C., Liu, H., Wang, J., Zou, B., and Zhu, H., 2012, "Crack propagation simulation in microstructure of ceramic tool materials," Computational Materials Science, 54(1), pp. 150-156. DOI: 10.1016/j.commatsci.2011.10.039

[3] Vazic, B., Wang, H., Diyaroglu, C., Oterkus, S., and Oterkus, E., 2017, "Dynamic propagation of a macrocrack interacting with parallel small cracks," AIMS Materials Science, 4(1), pp. 118-136. DOI: 10.3934/matersci.2017.1.118

[4] Basoglu, M. F., Zerin, Z., Kefal, A., and Oterkus, E., 2019, "A computational model of peridynamic theory for deflecting behavior of crack propagation with micro-cracks," Computational Materials Science, 162, pp. 33-46. DOI:

10.1016/j.commatsci.2019.02.032

[5] Li, X., Yang, H., Zan, X., Li, X., and Jiang, X., 2018, "Effect of a micro-crack on the kinked macro-crack," Theoretical and Applied Fracture Mechanics, 96, pp. 468-475. DOI: 10.1016/j.tafmec.2018.04.003

[6] Loehnert, S., and Belytschko, T., 2007, "Crack shielding and amplification due to multiple microcracks interacting with a macrocrack," International Journal of Fracture, 145(1), pp. 1-8. DOI: 10.1007/s10704-007-9094-1

[7] Brencich, A., and Carpinteri, A., 1998, "Stress field interaction and strain energy distribution between a stationary main crack and its process zone," Engineering Fracture Mechanics, 59(6), pp. 797-814. DOI: 10.1016/S0013-7944(97)00158-6

[8] Bleyer, J., Roux-Langlois, C., and Molinari, J. F., 2017, "Dynamic crack propagation with a variational phase-field model: limiting speed, crack branching and velocitytoughening mechanisms," International Journal of Fracture, 204(1), pp. 79-100. DOI: 10.1007/s10704-016-0163-1

[9] Rose, L. R. F., 1986, "Effective Fracture Toughness of Microcracked Materials," Journal of the American Ceramic Society, 69(3), pp. 212-214. DOI: 10.1111/j.11512916.1986.tb07409.x

[10] Li, X., Li, X., and Jiang, X., 2017, "Influence of a micro-crack on the finite macrocrack," Engineering Fracture Mechanics, 177, pp. 95-103. DOI: 10.1016/j.engfracmech.2017.03.037 
[11] Xiaotao, L., Xu, L., Hongda, Y., and Xiaoyu, J., 2017, "Effect of micro-cracks on plastic zone ahead of the macro-crack tip," Journal of Materials Science, 52(23), pp. 1349013503. DOI: $10.1007 /$ s10853-017-1440-8

[12] Rubinstein, A. A., 1985, "Macrocrack interaction with semi-infinite microcrack array," International Journal of Fracture, 27(2), pp. 113-119.

[13] Ducourthial, E., Bouchaud, E., and Chaboche, J. L., 2000, "Influence of microcracks on a propagation of macrocracks," Computational Materials Science, 19(1-4), pp. 229234. DOI: 10.1016/s0927-0256(00)00159-2

[14] Petrova, V., Tamuzs, V., and Romalis, N., 2000, "A survey of macro-microcrack interaction problems," Applied Mechanics Reviews, 53(5), pp. 117-146. DOI: 10.1115/1.3097344

[15] Soh, A. K., and Yang, C. H., 2004, "Numerical modeling of interactions between a macro-crack and a cluster of micro-defects," Engineering Fracture Mechanics, 71(2), pp. 193-217. DOI: 10.1016/S0013-7944(03)00097-3

[16] Kumar, S., and Curtin, W. A., 2007, "Crack interaction with microstructure," Materials Today, 10(9), pp. 34-44. DOI: 10.1016/S1369-7021(07)70207-9

[17] Gong, S. X., 1994, “Microcrack interaction with a finite main crack: An exact formulation," International Journal of Fracture, 66(3). DOI: 10.1007/BF00042592

[18] Laures, J. P., and Kachanov, M., 1991, "Three-dimensional interactions of a crack front with arrays of penny-shaped microcracks," International Journal of Fracture, 48(4), pp. 255-279. DOI: 10.1007/BF00012916

[19] Tamuzs, V. P., and Petrova, V. E., 2002, "On macrocrack-microdefect interaction," International Applied Mechanics, 38(10), pp. 1157-1177. DOI:

10.1023/A:1022250111016

[20] Lorentz, E., 2008, "A mixed interface finite element for cohesive zone models," Computer Methods in Applied Mechanics and Engineering, 198(2), pp. 302-317. DOI: 10.1016/j.cma.2008.08.006

[21] Unosson, M., Olovsson, L., and Simonsson, K., 2006, "Failure modelling in finite element analyses: Element erosion with crack-tip enhancement," Finite Elements in Analysis and Design, 42(4), pp. 283-297. DOI: 10.1016/j.finel.2005.07.001

[22] Lancaster, I. M., Khalid, H. A., and Kougioumtzoglou, I. A., 2013, "Extended FEM modelling of crack propagation using the semi-circular bending test," Construction and Building Materials, 48, pp. 270-277. DOI: 10.1016/j.conbuildmat.2013.06.046 
[23] Zhou, X., Wang, Y., and Qian, Q., 2016, "Numerical simulation of crack curving and branching in brittle materials under dynamic loads using the extended non-ordinary state-based peridynamics," European Journal of Mechanics, A/Solids, 60, pp. 277-299. DOI: 10.1016/j.euromechsol.2016.08.009

[24] Moës, N., Dolbow, J., and Belytschko, T., 1999, "A finite element method for crack growth without remeshing," International Journal for Numerical Methods in Engineering, 46(1), pp. 131-150. DOI: 10.1002/(SICI)10970207(19990910)46:1<131::AID-NME726>3.0.CO;2-J

[25] Belytschko, T., Chen, H., Xu, J., and Zi, G., 2003, "Dynamic crack propagation based on loss of hyperbolicity and a new discontinuous enrichment," International Journal for Numerical Methods in Engineering, 58(12), pp. 1873-1905. DOI: 10.1002/nme.941

[26] Budyn, É., Zi, G., Moës, N., and Belytschko, T., 2004, "A method for multiple crack growth in brittle materials without remeshing," International Journal for Numerical Methods in Engineering, 61(10), pp. 1741-1770. DOI: 10.1002/nme.1130

[27] Zhuang, Z., and Cheng, B. B., 2011, "Equilibrium state of mode-I sub-interfacial crack growth in bi-materials," International Journal of Fracture, 170(1), pp. 27-36. DOI: 10.1007/s10704-011-9599-5

[28] Zhuang, Z., and Cheng, B. B., 2011, "Development of X-FEM methodology and study on mixed-mode crack propagation," Acta Mechanica Sinica/Lixue Xuebao, 27(3), pp. 406-415. DOI: 10.1007/s10409-011-0436-x

[29] Zhuang, Z., and Cheng, B. B., 2011, "A novel enriched CB shell element method for simulating arbitrary crack growth in pipes," Science China: Physics, Mechanics and Astronomy, 54(8), pp. 1520-1531. DOI: 10.1007/s11433-011-4385-y

[30] Wang, H., Liu, Z., Xu, D., Zeng, Q., Zhuang, Z., and Chen, Z., 2016, “Extended finite element method analysis for shielding and amplification effect of a main crack interacted with a group of nearby parallel microcracks," International Journal of Damage Mechanics, 25(1), pp. 4-25. DOI: 10.1177/1056789514565933

[31] Huo, J., Zhang, Z., Meng, Z., Xue, L., Jia, G., and Chen, J., 2019, “A time-integral crack propagation model considering thickness effect," IEEE Access, 7, pp. 41078-41089. DOI: 10.1109/ACCESS.2019.2906461

[32] Bobaru, F., and Zhang, G., 2015, "Why do cracks branch? A peridynamic investigation of dynamic brittle fracture," International Journal of Fracture, 196(1-2), pp. 59-98. DOI: 10.1007/s10704-015-0056-8 
[33] Rabczuk, T., Zi, G., Bordas, S., and Nguyen-Xuan, H., 2010, “A simple and robust three-dimensional cracking-particle method without enrichment," Computer Methods in Applied Mechanics and Engineering, 199(37-40), pp. 2437-2455. DOI:

10.1016/j.cma.2010.03.031

[34] Kosteski, L., Barrios D'Ambra, R., and Iturrioz, I., 2012, “Crack propagation in elastic solids using the truss-like discrete element method," International Journal of Fracture, 174(2), pp. 139-161. DOI: 10.1007/s10704-012-9684-4

[35] Braun, M., and Fernández-Sáez, J., 2014, “A new 2D discrete model applied to dynamic crack propagation in brittle materials," International Journal of Solids and Structures, 51(21-22), pp. 3787-3797. DOI: 10.1016/j.ijsolstr.2014.07.014

[36] Kalthoff, J. F., and Winkler, S., 1988, "Failure mode transition at high rates of loading," Impact Loading and Dynamic Behavior of Materials, 1, pp. 185-195.

[37] Silling, S. A., and Askari, E., 2005, "A meshfree method based on the peridynamic model of solid mechanics," Computers and Structures, 83(17-18), pp. 1526-1535. DOI: 10.1016/j.compstruc.2004.11.026

[38] Silling, S. A., 2000, "Reformulation of elasticity theory for discontinuities and longrange forces," Journal of the Mechanics and Physics of Solids, 48(1), pp. 175-209. DOI: 10.1016/S0022-5096(99)00029-0

[39] Javili, A., Morasata, R., Oterkus, E., and Oterkus, S., 2019, "Peridynamics review," Mathematics and Mechanics of Solids, 24(11), pp. 3714-3739. DOI:

$10.1177 / 1081286518803411$

[40] Silling, S. A., and Lehoucq, R. B., 2008, "Convergence of peridynamics to classical elasticity theory," Journal of Elasticity, 93(1), pp. 13-37. DOI: 10.1007/s10659-008-91633

[41] Kilic, B. and Madenci, E., 2010, "Coupling of peridynamic theory and the finite element method," Journal of Mechanics of Materials and Structures, 5(5), pp. 707-733. DOI: $10.2140 /$ jomms.2010.5.707

[42] Oterkus, E., Madenci, E., Weckner, O., Silling, S. A., Bogert, P., and Tessler, A., 2012, "Combined finite element and peridynamic analyses for predicting failure in a stiffened composite curved panel with a central slot," Composite Structures, 94(3), pp. 839-850. DOI: 10.1016/j.compstruct.2011.07.019

[43] Bobaru, F., Ha, Y. D., and Hu, W., 2012, "Damage progression from impact in layered glass modeled with peridynamics," Central European Journal of Engineering, 2(4), pp. 551-561. DOI: 10.2478/s13531-012-0020-6 
[44] Ghajari, M., Iannucci, L., and Curtis, P., 2014, "A peridynamic material model for the analysis of dynamic crack propagation in orthotropic media," Computer Methods in Applied Mechanics and Engineering, 276, pp. 431-452. DOI: 10.1016/j.cma.2014.04.002

[45] Oterkus, S., Madenci, E., and Agwai, A., 2014, "Fully coupled peridynamic thermomechanics," Journal of the Mechanics and Physics of Solids, 64(1), pp. 1-23. DOI: 10.1016/j.jmps.2013.10.011

[46] Oterkus, S., Madenci, E., and Agwai, A., 2014, "Peridynamic thermal diffusion," Journal of Computational Physics, 265, pp. 71-96. DOI: 10.1016/j.jcp.2014.01.027

[47] De Meo, D., Russo, L., and Oterkus, E., 2017, "Modeling of the onset, propagation, and interaction of multiple cracks generated from corrosion pits by using peridynamics," Journal of Engineering Materials and Technology, Transactions of the ASME, 139(4), pp. 1-9. DOI: 10.1115/1.4036443.

[48] Diyaroglu, C., Oterkus, E., Madenci, E., Rabczuk, T., and Siddiq, A., 2016, "Peridynamic modeling of composite laminates under explosive loading," Composite Structures, 144, pp. 14-23. DOI: 10.1016/j.compstruct.2016.02.018

[49] Madenci, E. and Oterkus, E., 2014, "Peridynamic theory and its applications", New York, NY, USA: Springer. DOI: 10.1007/978-1-4614-8465-3

[50] Silling, S. A., 2003, "Dynamic fracture modeling with a meshfree peridynamic code," in Computational Fluid and Solid Mechanics 2003, pp. 641-644. DOI: 10.1016/B978008044046-0.50157-3

[51] Kalthoff, J. F., 2000, "Modes of dynamic shear failure in solids," International Journal of Fracture, 101(1-2), pp. 1-31. DOI: 10.1023/A:1007647800529

[52] Silling, S. A., Epton, M., Weckner, O., Xu, J., and Askari, E., 2007, "Peridynamic states and constitutive modeling," Journal of Elasticity, 88(2), pp. 151-184. DOI: 10.1007/s10659-007-9125-1

[53] Ren, H., Zhuang, X., Cai, Y., and Rabczuk, T., 2016, “Dual-horizon peridynamics," International Journal for Numerical Methods in Engineering, 108(12), pp. 1451-1476. DOI: $10.1002 / \mathrm{nme} .5257$

[54] Ren, H., Zhuang, X., and Rabczuk, T., 2017, “Dual-horizon peridynamics: A stable solution to varying horizons," Computer Methods in Applied Mechanics and Engineering, 318, pp. 762-782. DOI: 10.1016/j.cma.2016.12.031 
[55] Amani, J., Oterkus, E., Areias, P., Zi, G., Nguyen-Thoi, T., and Rabczuk, T., 2016, “A non-ordinary state-based peridynamics formulation for thermoplastic fracture," International Journal of Impact Engineering, 87, pp. 83-94. DOI:

10.1016/j.ijimpeng.2015.06.019

[56] Gu, X., Zhang, Q., and Xia, X., 2017, “Voronoi-based peridynamics and cracking analysis with adaptive refinement," International Journal for Numerical Methods in Engineering, 112(13), pp. 2087-2109. DOI: 10.1002/nme.5596

[57] Guo, J. S. and Gao, W. C., 2019, "Study of the Kalthoff-Winkler experiment using an ordinary state-based peridynamic model under low velocity impact," Advances in Mechanical Engineering, 11(5), pp. 1-11. DOI: 10.1177/1687814019852561

[58] Trask, N., You, H., Yu, Y., and Parks, M. L., 2019, “An asymptotically compatible meshfree quadrature rule for nonlocal problems with applications to peridynamics," Computer Methods in Applied Mechanics and Engineering, 343, pp. 151-165. DOI: 10.1016/j.cma.2018.08.016

[59] Wang, H., Xu, Y., and Huang, D., 2019, "A non-ordinary state-based peridynamic formulation for thermo-visco-plastic deformation and impact fracture," International Journal of Mechanical Sciences, 159, pp. 336-344. DOI: 10.1016/j.ijmecsci.2019.06.008 


\section{Figure Captions List}

Fig. 1 Position and force vectors of two material points in the reference state and after deformation

Fig. 2 The definition of a micro-crack plane (red thick continuous line) that is located between material points. The broken bonds of a material point between the family members in its horizon and which intersect with the micro-crack plane are shown as red lines with arrows.

Fig. 3 An algorithm for the determination process of broken bonds due to microcracks

Fig. 4 (a) The Kalthoff and Winkler [36] experimental setup, (b) Peridynamic discretization model

Fig. 5 Geometric details of the benchmark study: crescent-like micro-crack pattern

Fig. 6 (a) The crack propagation in Kalthoff-Winkler experiment (without microcrack case) at $91.4 \mu \mathrm{s}$ and (c) at $95.7 \mu \mathrm{s}$. (b) The crack propagation of benchmark problem at $91.4 \mu \mathrm{s}$ and (d) at $95.7 \mu \mathrm{s}$

Fig. 7 Geometric details of the micro-crack pattern in the reference zone $A_{0}$ with the reference density $n_{0}$

Fig.8 (a) The crack path of the simulation of Kalthoff-Winkler experiment, (b) $n_{0} \times 0.75,(\mathrm{c}) n_{0} \times 1$, and (d) $n_{0} \times 1.25$ cases at $91.4 \mu \mathrm{s}\left(1050^{\text {th }}\right.$ timestep) 
Fig. 9 The macro-crack propagation velocities of without micro-crack and with micro crack cases with densities $n_{0} \times\{0.75,1,1.25\}$ between 52.2 and 91.4 $\mu$ s. The initial and maximum velocities are shown with black boxes.

Fig. 10 Geometric details of the micro-crack pattern in $A_{0}, A_{1}, A_{2}$ regions with a micro-crack density of $n_{0}$

Fig. 11 (a) The crack path of the simulation of Kalthoff-Winkler experiment, (b) $A_{1}$ (c) $A_{0}$, and (d) $A_{2}$ cases at $91.4 \mu \mathrm{s}\left(1050^{\text {th }}\right.$ timestep)

Fig. 12 The macro-crack propagation velocities of without micro-cracks, $A_{1}, A_{0}$, and $A_{2}$ cases between 52.2 and $91.4 \mu$ s. The initial and maximum velocities are shown with black boxes. 
Journal of Engineering Materials and Technology

\section{Table Caption List}

Table $1 \quad$ Material properties of maraging steel 


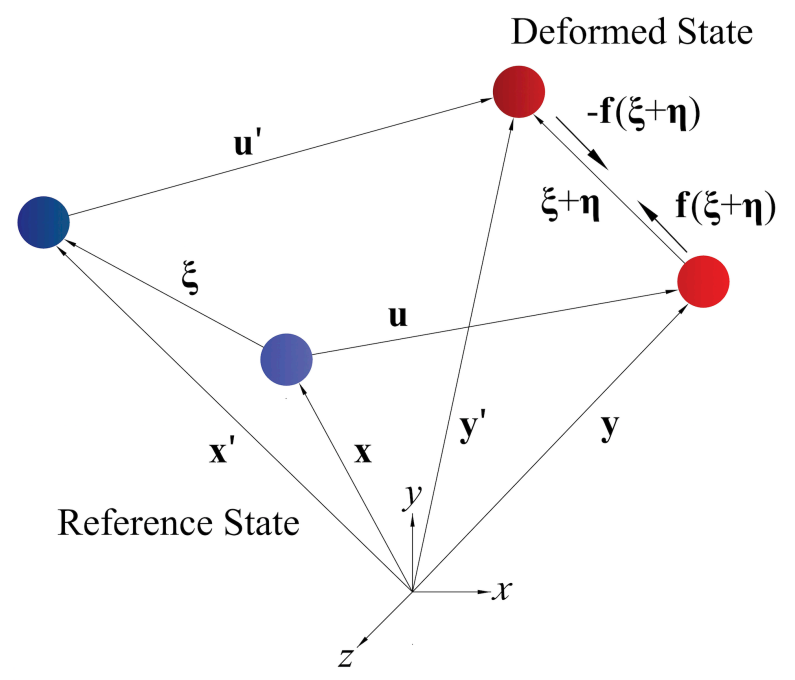

Figure 1. Position and force vectors of two material points in the reference state and after deformation 


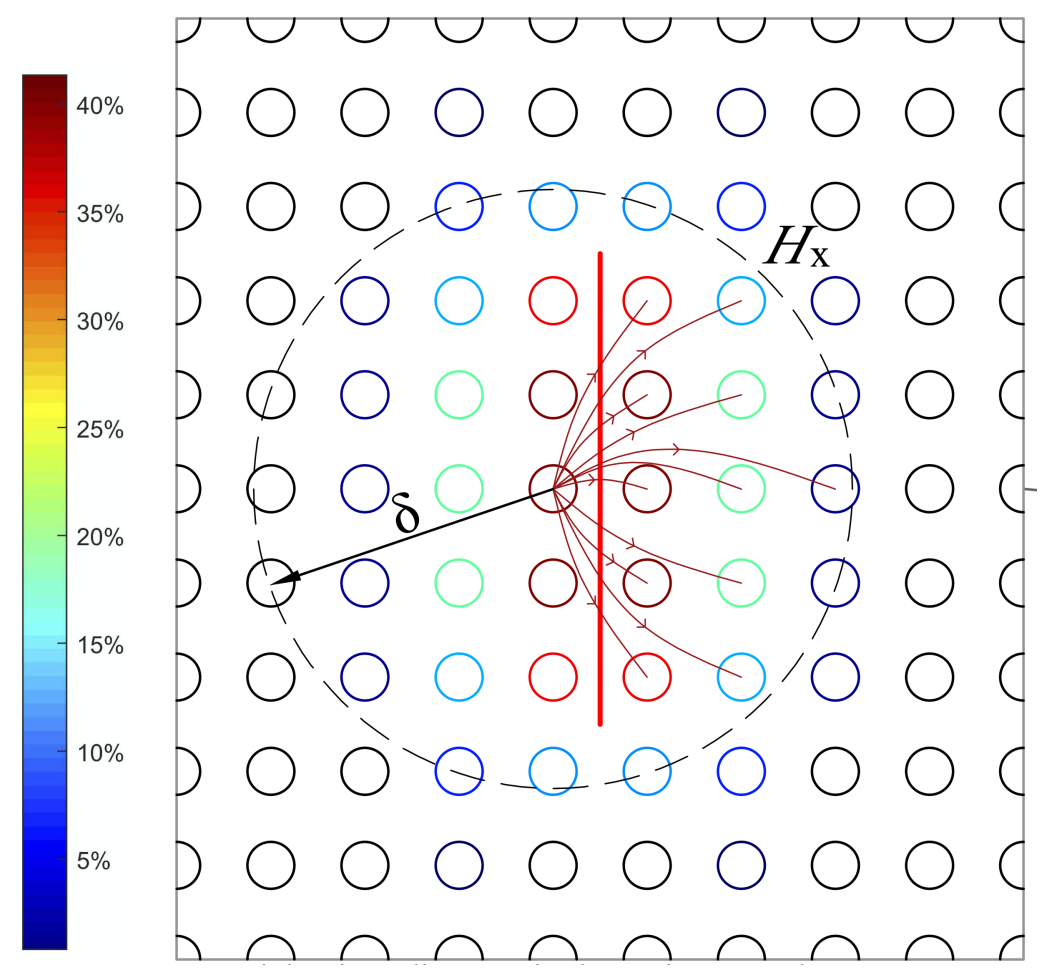

Figure 2. The definition of a micro-crack plane (red thick continuous line) that is located between material points. The broken bonds of a material point between the family members in its horizon and which intersect with the micro-crack plane are shown as red lines with arrows. 


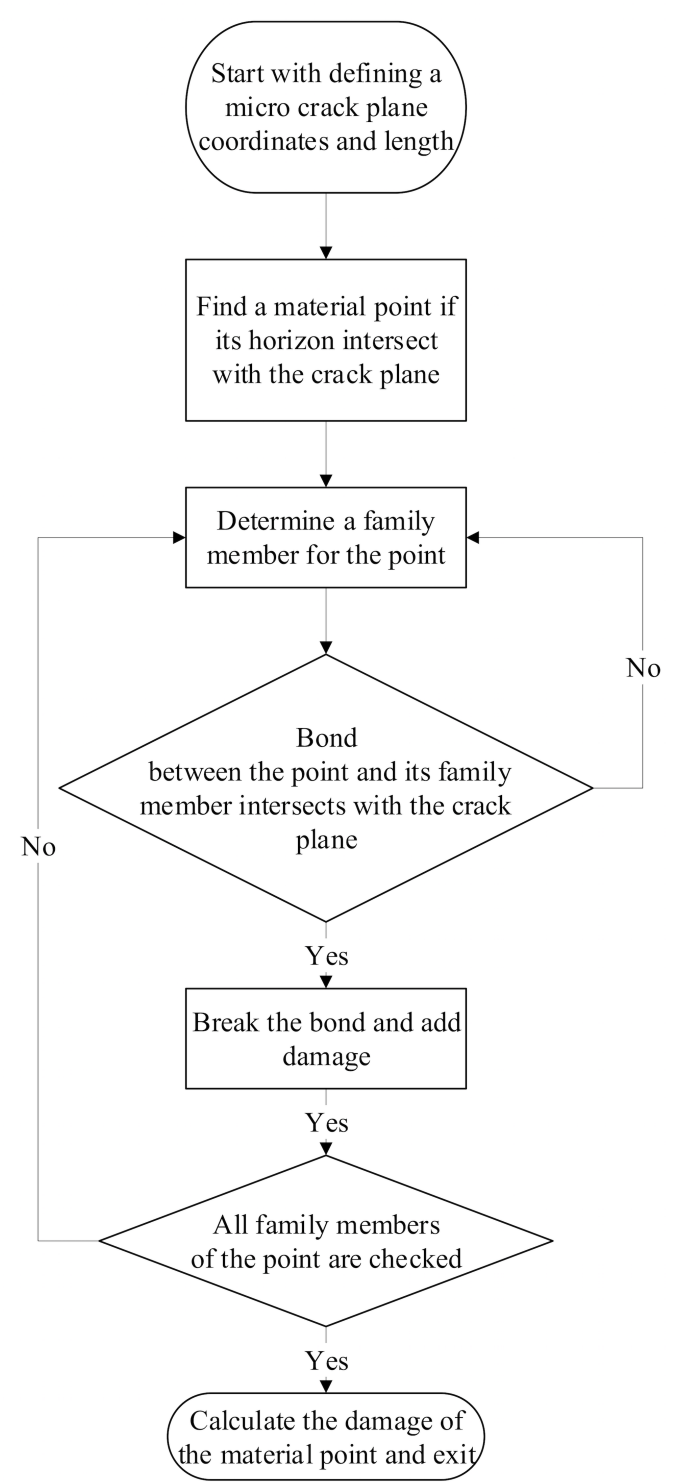

Figure 3. An algorithm for the determination process of broken bonds due to microcracks 
Journal of Engineering Materials and Technology

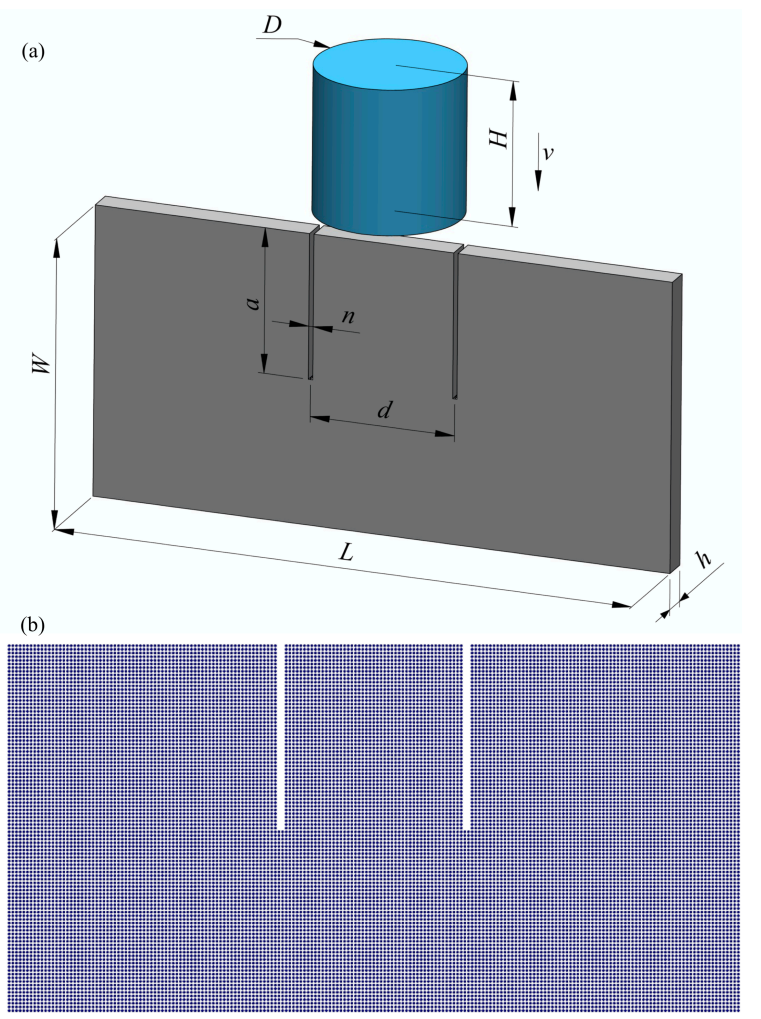

Figure 4. (a) The Kalthoff and Winkler [36] experimental setup, (b) Peridynamic discretization model 

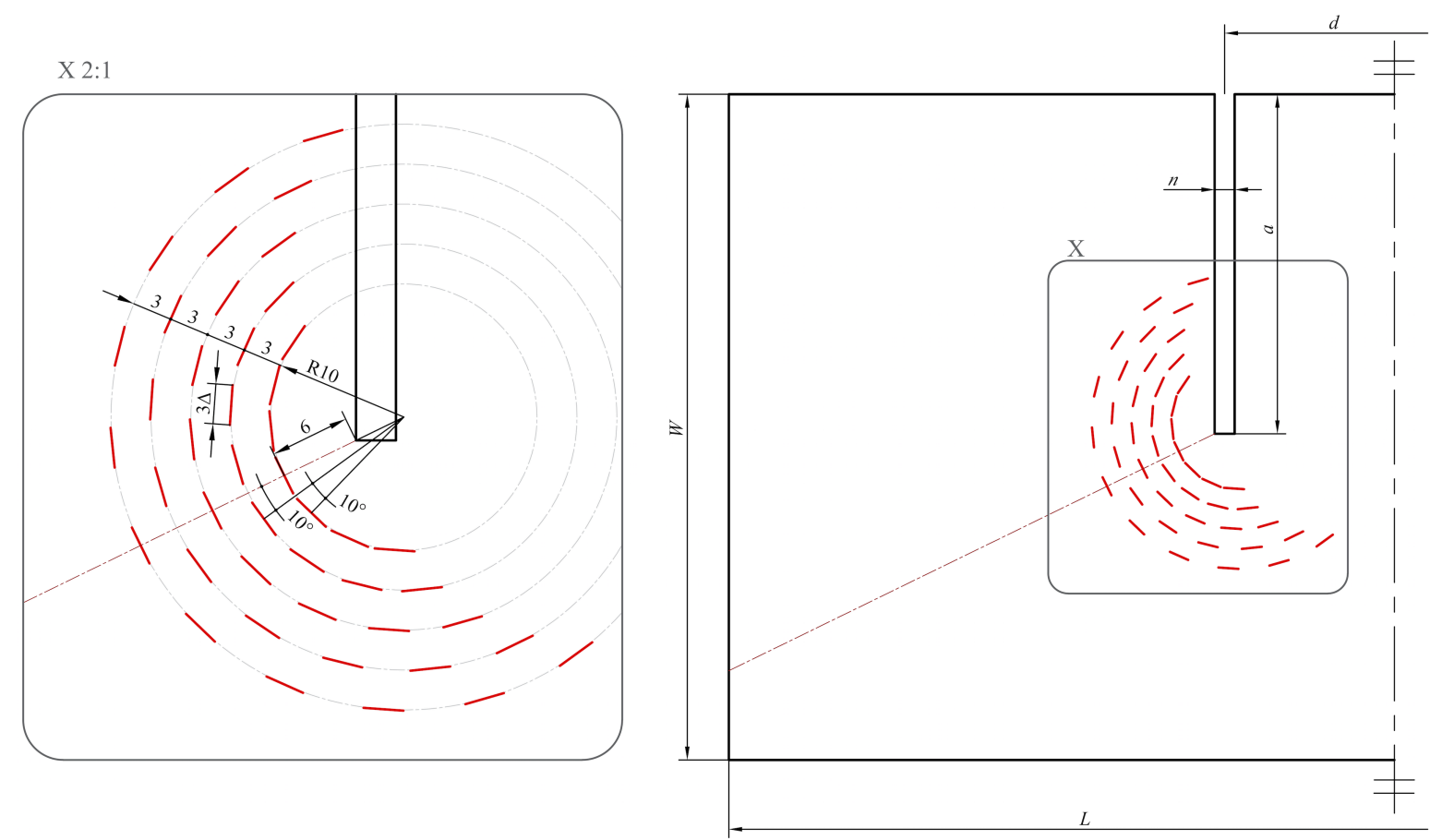

Figure 5. Geometric details of the benchmark study: crescent-like micro-crack pattern 


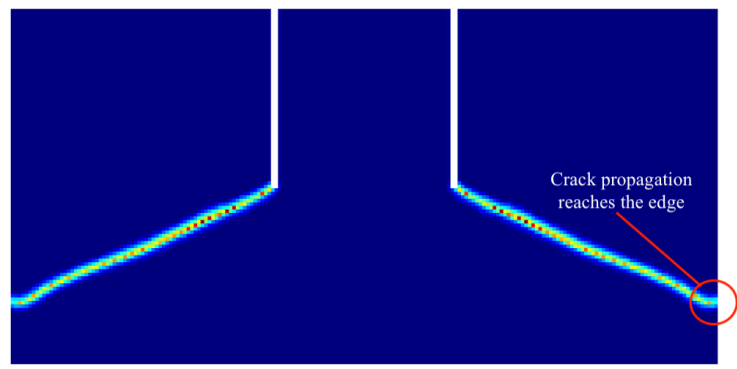

a) Without micro-crack at $91.4 \mu \mathrm{s}$

Damage
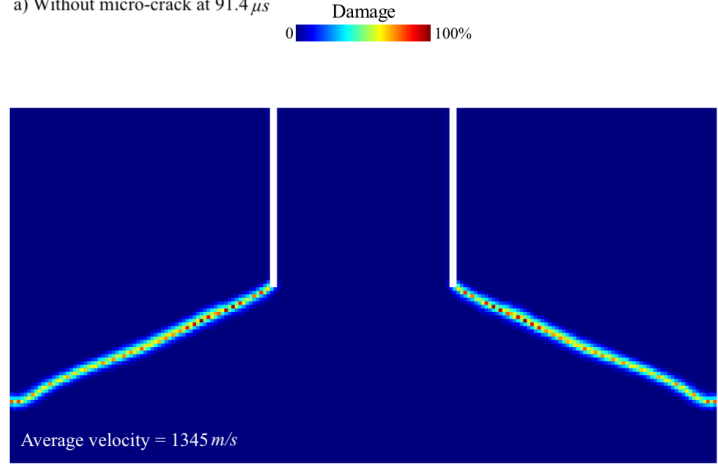

c) Without micro-crack at $95.7 \mu \mathrm{s}$
Damage
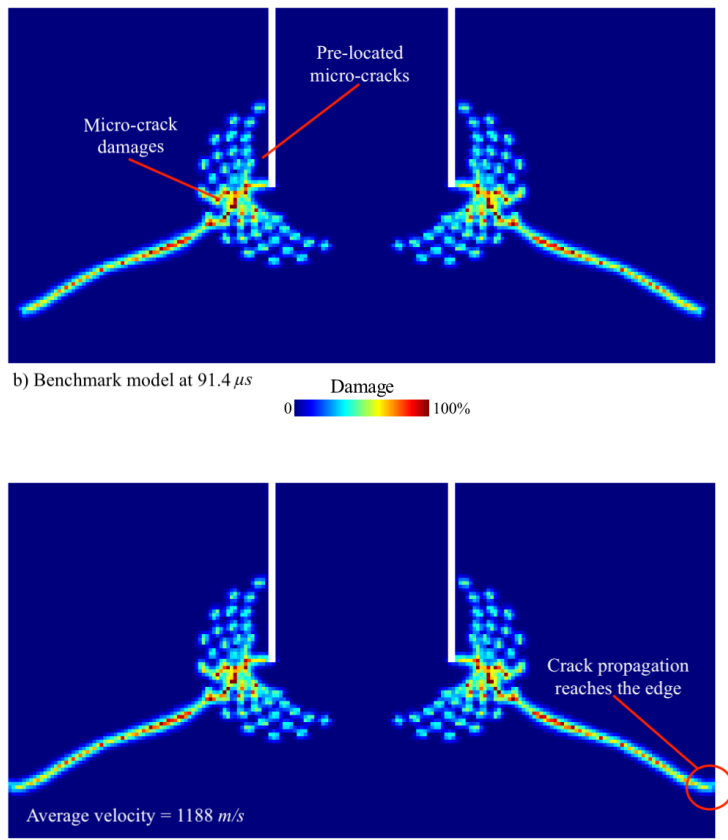

d) Benchmark model at $95.7 \mu \mathrm{s} \quad$ Damage $\%$ 100

Figure 6. (a) The crack propagation in Kalthoff-Winkler experiment (without micro-crack case) at $91.4 \mu \mathrm{s}$ and (c) at $95.7 \mu \mathrm{s}$. (b) The crack propagation of benchmark problem at $91.4 \mu \mathrm{s}$ and (d) at $95.7 \mu \mathrm{s}$ 

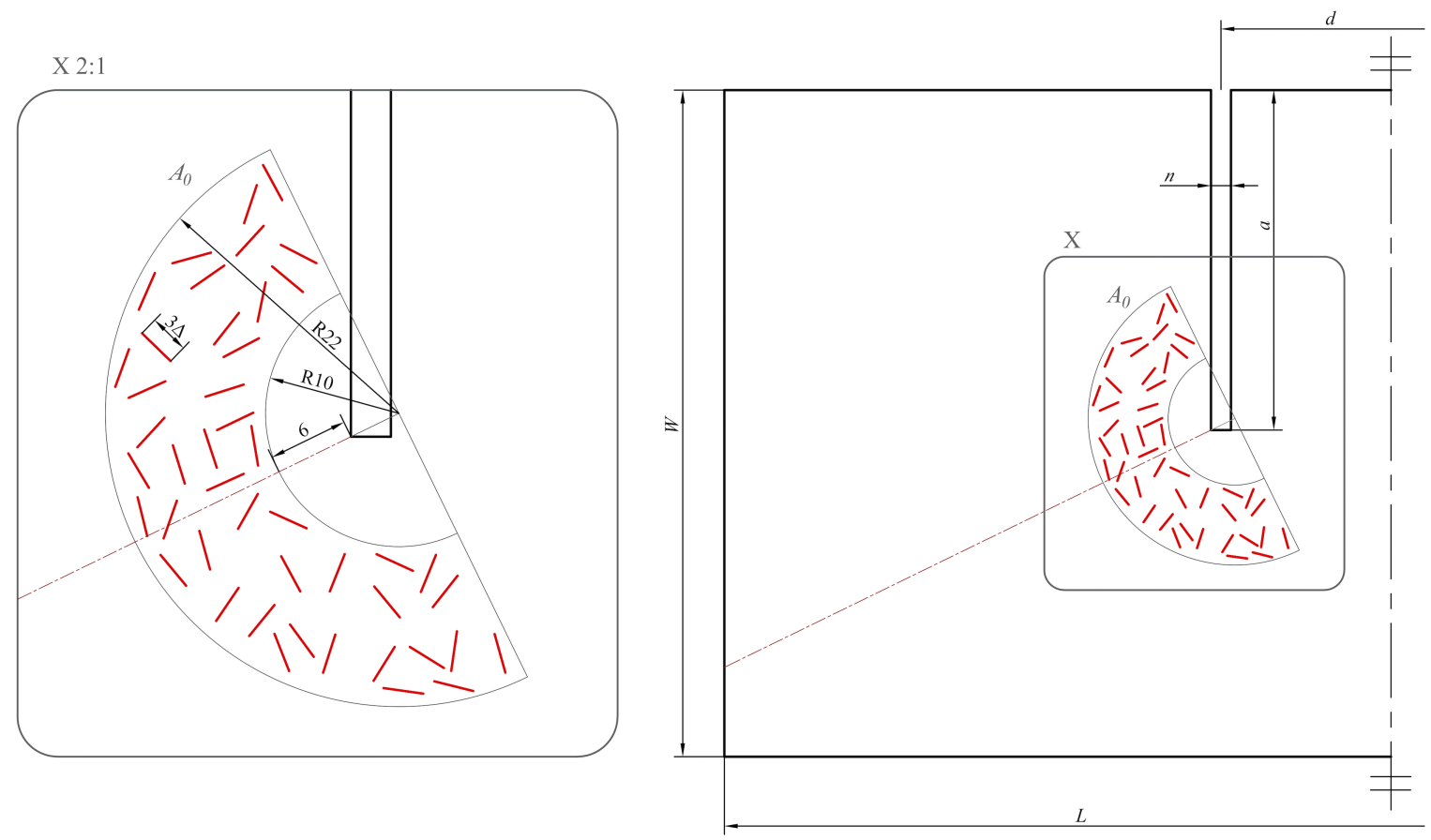

Figure 7. Geometric details of the micro-crack pattern in the reference zone $A_{0}$ with the reference density $n_{0}$ 

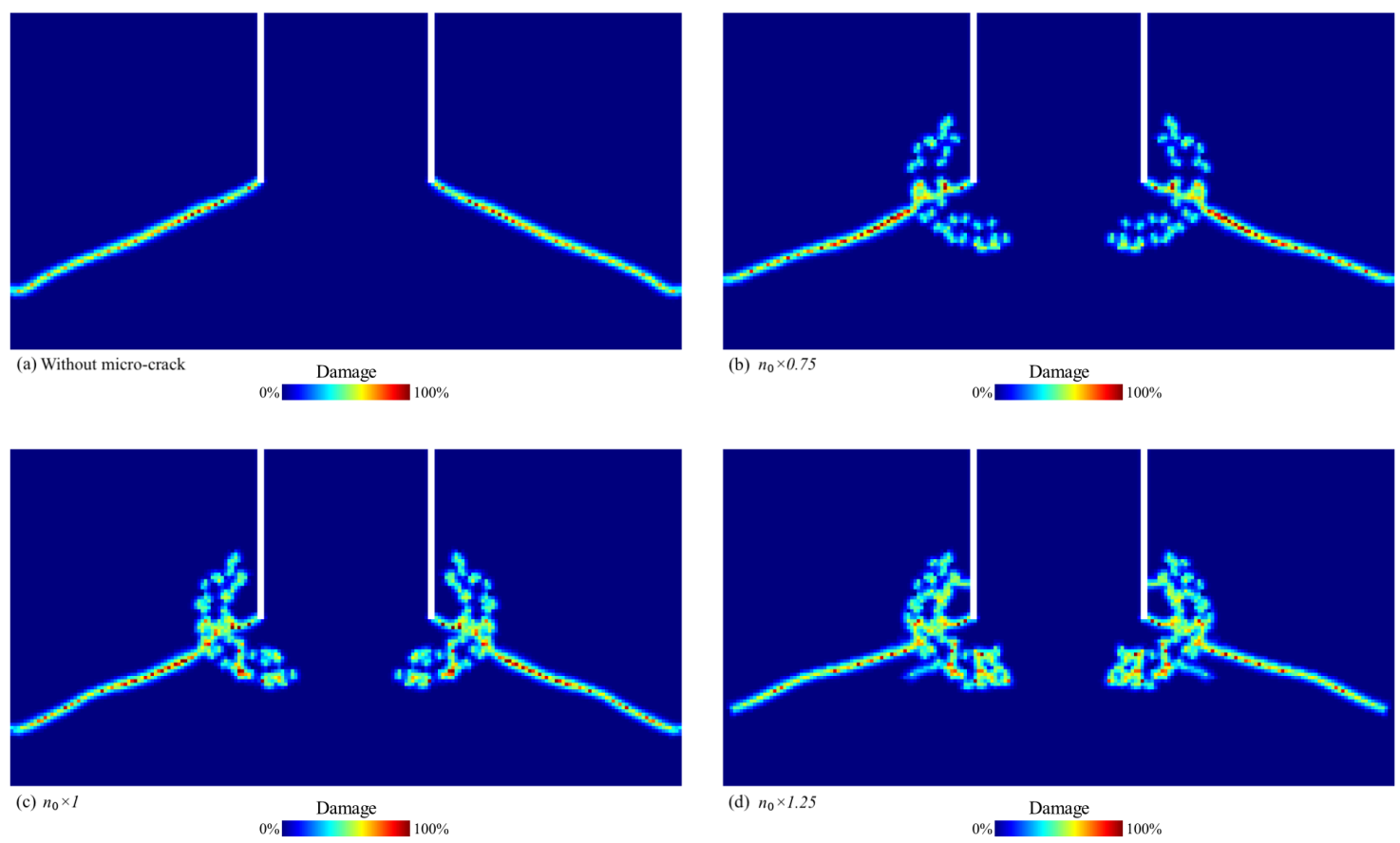

Figure 8. (a) The crack path of the simulation of Kalthoff-Winkler experiment, (b) $n_{0} \times 0.75$, (c) $n_{0} \times 1$, and (d) $n_{0} \times 1.25$ cases at $91.4 \mu \mathrm{s}\left(1050^{\text {th }}\right.$ timestep) 
Journal of Engineering Materials and Technology

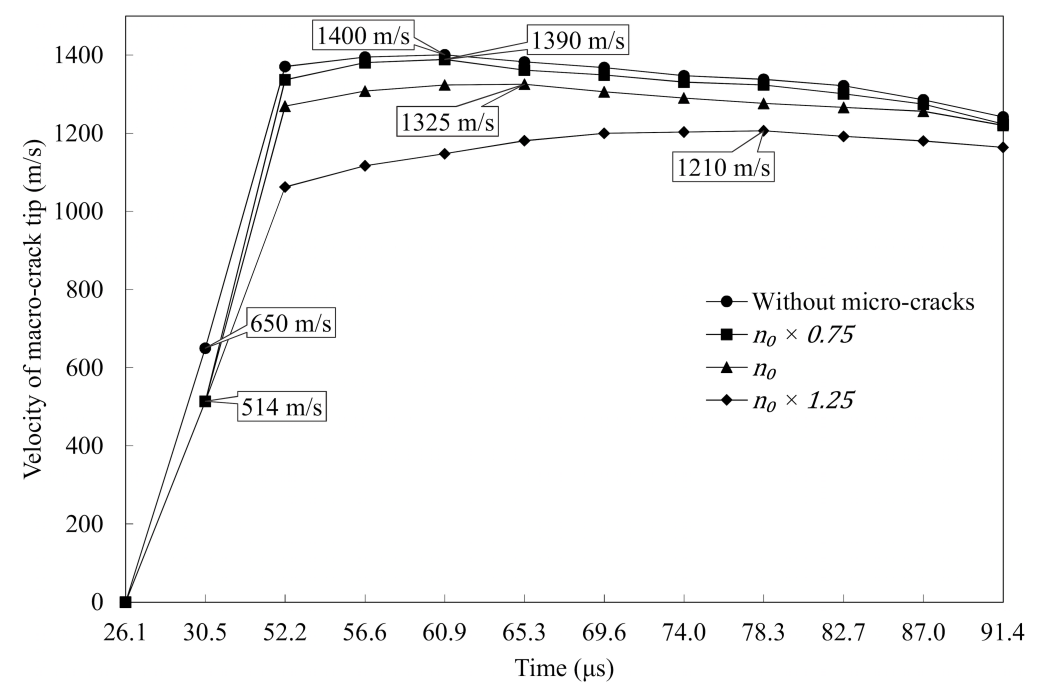

Figure 9. The macro-crack propagation velocities of without micro-crack and with micro crack cases with densities $n_{0} \times\{0.75,1,1.25\}$ between 52.2 and $91.4 \mu \mathrm{s}$. The initial and maximum velocities are shown with black boxes. 

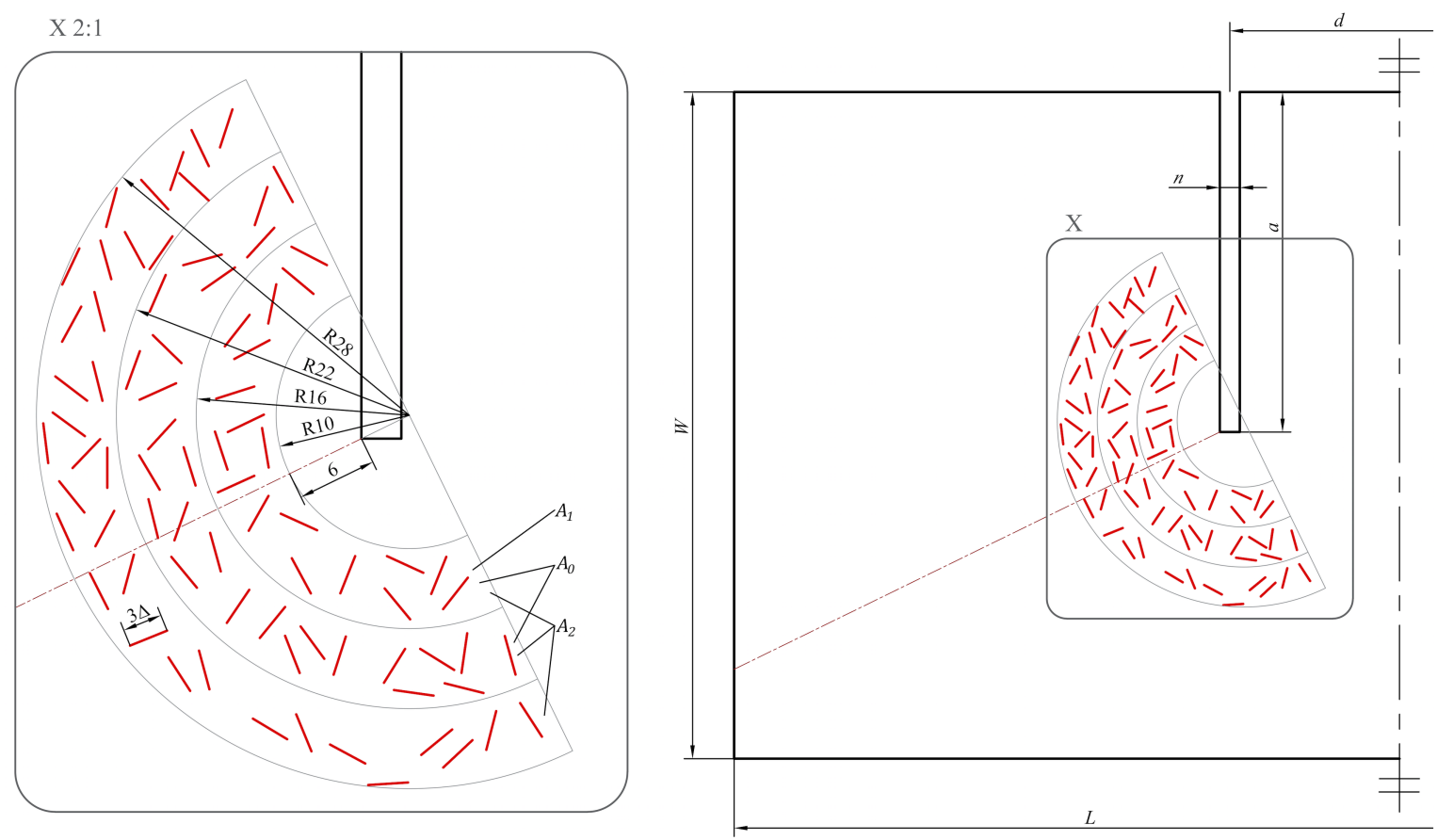

Figure 10. Geometric details of the micro-crack pattern in $A_{0}, A_{1}, A_{2}$ regions with a micro-crack density of $n_{0}$ 

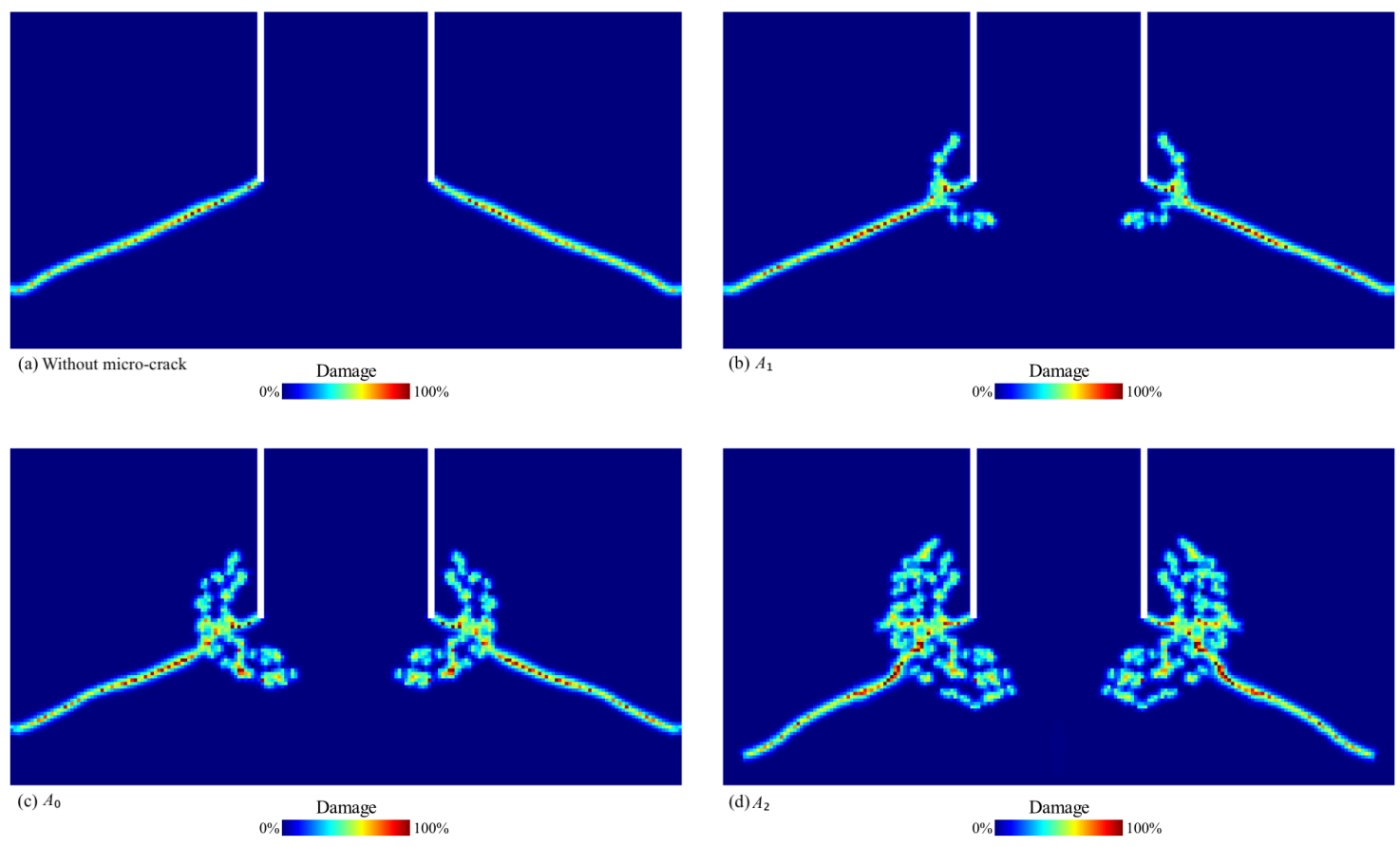

Figure 11. (a) The crack path of the simulation of Kalthoff-Winkler experiment, (b) $A_{1}$ (c) $A_{0}$, and (d) $A_{2}$ cases at $91.4 \mu s\left(1050^{\text {th }}\right.$ timestep) 
Journal of Engineering Materials and Technology

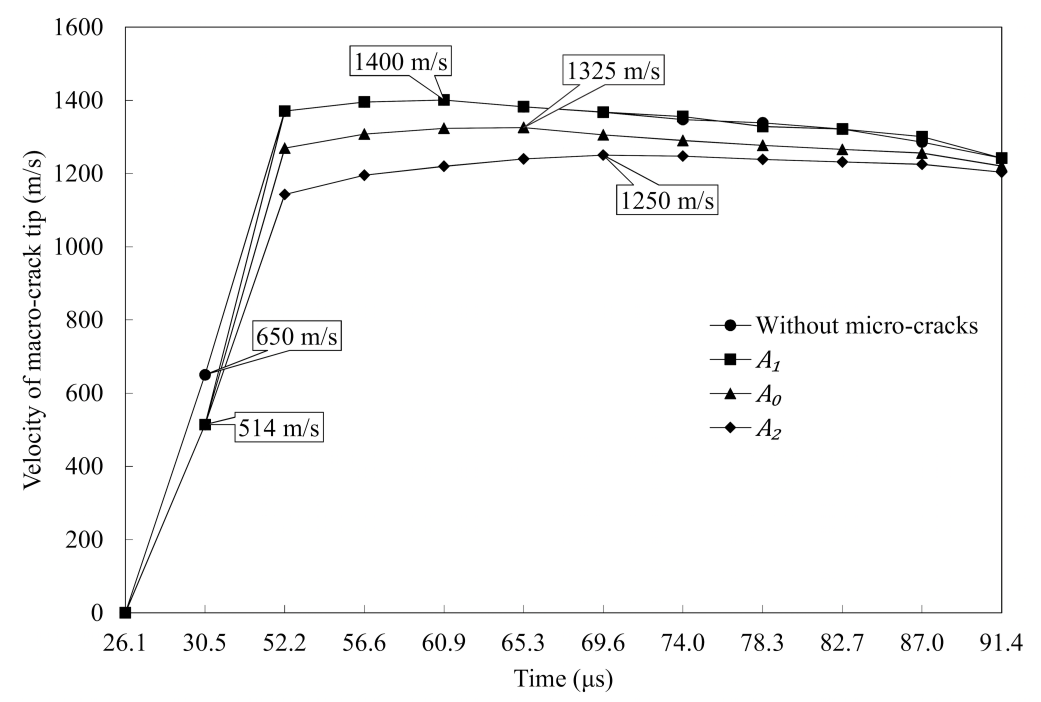

Figure 12. The macro-crack propagation velocities of without micro-cracks, $A_{1}, A_{0}$, and $A_{2}$ cases between 52.2 and $91.4 \mu \mathrm{s}$. The initial and maximum velocities are shown with black boxes. 
Journal of Engineering Materials and Technology

Table 1. Material properties of maraging steel

Young's Modulus $E$

Poisson's ratio $v$

Mass density $\rho$

$191 \mathrm{GPa}$

0.25

$8000 \mathrm{~kg} / \mathrm{m}^{3}$ 